\title{
Sphenoidal Sinusitis
}

National Cancer Institute

\section{Source}

National Cancer Institute. Sphenoidal Sinusitis. NCI Thesaurus. Code C35031.

An acute or chronic inflammatory process affecting the mucous membrane of the sphenoid sinus. 